\title{
Review on Application of Hybrid Energy Storage Based on Ultracapacitor
}

\author{
Yang Xiao-bin ${ }^{1, a}$,Li He-ming ${ }^{2, b}$, Jiang Zhe ${ }^{3, c}$, Wang He $\mathrm{H}^{4, \mathrm{~d}}$, Yin-Zhongdong ${ }^{5, \mathrm{e}}$ \\ 1,2,3,5Beinong Rd 2,Changping District,North China Electric Power University, Beijing,China \\ ${ }^{4}$ Qinghexiaoying East Rd 15,China Electric Power Research Institute, Haidian District,Beijing,China \\ aruben203@163.com, bliheming57@263.net, 'wanghe@epri.sgcc.com.cn
}

Keywords: Ultracapacitor, lead-acid battery, hybrid energy storage system, application.

\begin{abstract}
Characteristics of ultracapacitor and classic model have been introduced in this paper. Due to its superior performance, ultracapacitor is used for hybrid energy storage system with lead-acid battery. The performance and potential application of hybrid energy storage system have been elaborated, which make some contribution to the promotion and application of energy storage technology.
\end{abstract}

\section{Introduction}

Ultracapacitor known as electric double layer capacitor ${ }^{[2,5-7]}$ (EDLC) is a kind of novel energy storage element, which contains many advantages that battery and traditional capacitor have, such as fast charge and discharge time, large capacity, long cycle life and other characteristics.

Table 1 Characteristics of ultracapacitor, electrostatic capacitor and battery ${ }^{[1]}$

\begin{tabular}{|c|c|c|c|c|c|c|}
\hline Device Name & $\begin{array}{c}\text { Discharge } \\
\text { time[s] }\end{array}$ & $\begin{array}{c}\text { Charge } \\
\text { time[s] }\end{array}$ & $\begin{array}{c}\text { specific } \\
\text { energy } \\
\text { [Wh/kg] }\end{array}$ & $\begin{array}{c}\text { specific } \\
\text { power } \\
\text { [W/kg] }\end{array}$ & $\begin{array}{c}\text { Efficiency } \\
{[\%]}\end{array}$ & Serve life \\
\hline Ultracapacitor & $(1 \sim 30) \mathrm{s}$ & $(1 \sim 30) \mathrm{s}$ & $1 \sim 10$ & $1000 \sim 2000$ & $0.9 \sim 0.95$ & $>10,000$ \\
\hline $\begin{array}{c}\text { Electrostatic } \\
\text { capacitor }\end{array}$ & $\left(10^{-6} \sim 10^{-3}\right) \mathrm{s}$ & $\left(10^{-6} \sim 10^{-3}\right) \mathrm{s}$ & $<0.1$ & $>10,000$ & 1.0 & Unlimited \\
\hline Battery & $(0.3 \sim 3) \mathrm{h}$ & $(1 \sim 5) \mathrm{h}$ & $20 \sim 100$ & $50 \sim 200$ & $0.7 \sim 0.85$ & $500 \sim 2000$ \\
\hline
\end{tabular}

Due to its superior performance, ultracapacitor has been playing a great role in energy storage and wind power generation, and it exists huge application potential in many fields, like electric vehicles, power system, and renewable generation, and ultracapacitor is drawing more and more attention in industries. According to different manufacturing process technologies, ultracapacitor can generally be classified as button-type(below 5F), wound-type(5 200F) and large-type(above 200F) ${ }^{[2]}$.

Button-type can discharge in a low current for a long time, generally used for low power electronic product. Wound-type and large-type are characteristic of high discharge current, can be used for emergency power supply, UPS, etc.

\section{Ultracapacitor model}

There are Debye model and transmission line model for ultracapacitor ${ }^{[5.6 .10,11]}$, which contain resistive and capacitive properties of ultracapacitor , these two models are made up of resistance and capacitor. Some models have considered its inductive performance, the related equivalent circuit constituted by the resistor, inductor and capacitor. However, in order to analyze and calculate easily, Classic equivalent model with serial resistor and shunt resistor is generally used ${ }^{[6]}$, when ignore its leakage current, we can only take into account serial resistor.

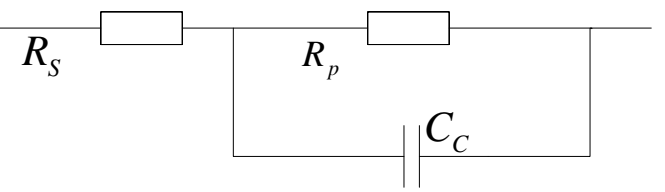

Fig.1 Classic equivalent model of ultracapacitor 
In Fig. $1 R_{s}$ is serial resistor, means internal resistance of ultracapacitor. $R_{p}$ is shunt resistor, stands for the loss of leakage current at the status of static storage. $C_{c}$ is the ideal equivalent capacitance.

\section{Hybrid energy storage system}

Although high energy density of traditional battery, it cannot be discharged deeply, and short life cycle, long discharge time, slow reaction to fluctuant power are its drawbacks. Ultracapacitor can compensate for the weaknesses of traditional battery, it is a novel energy storage component including characteristics of battery and traditional capacitor, EDLC has advantages of short charge and discharge time, large capacity, and long cycle life. Hybrid energy storage system can be established by battery combined with EDLC.

Hybrid energy storage system ${ }^{[4,9]}$ based on EDLC is characteristic of fast charge and discharge speed, rapid reaction to fluctuant load current. When load fluctuates, EDLC will bear most of load current, so that the current flow through battery is very small, under this condition, not only does energy consumed on resistance of battery is reduced, but also extends battery service life. In addition, if the out power is the same, compared to battery alone, hybrid energy storage system can reduce the equipped capacity of battery storage system alone.
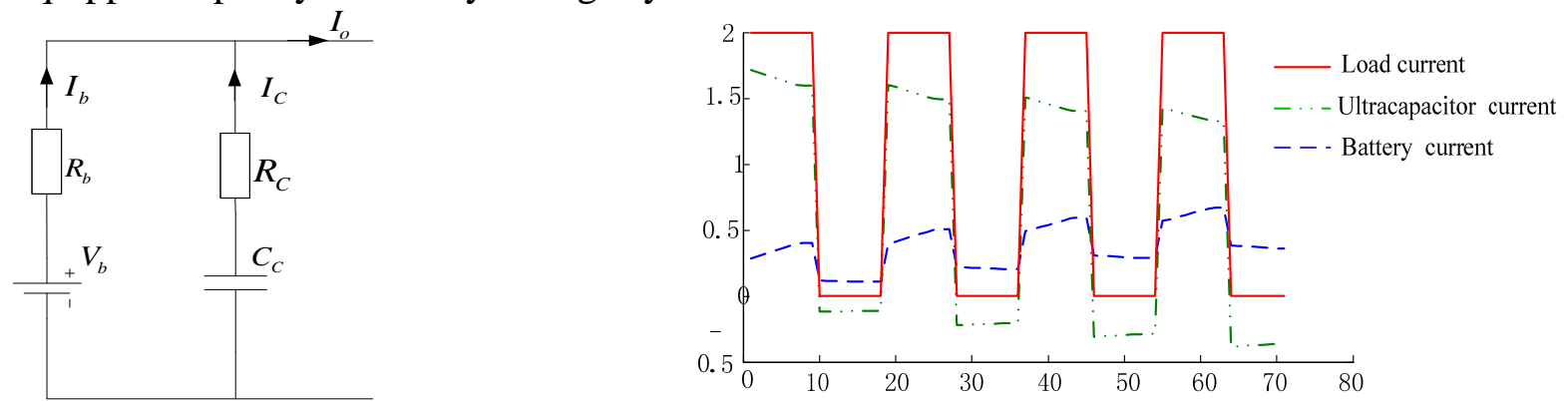

Fig.2 Equivalent circuit of hybrid energy storage system

Fig.3 Current of battery, ultracapacitor and load

According to paper [4], hybrid energy storage system made up of battery and ultracapacitor can obtain effective results in response to pulse load current and peak output power. The paper also analyzed energy savings and maximum extend discharge time of hybrid energy storage system. The formulas are as follows:

Energy savings $\Delta W$ formula:

$$
\begin{aligned}
& \Delta W=R_{b} D I_{0}^{2}\left[T_{b o}-(1-\varepsilon) T_{b c}\right] \\
& \varepsilon(D, m) \underset{f \rightarrow \infty}{\longrightarrow}(1-D) \frac{R_{b}}{R_{b}+\frac{R_{c}}{m}}
\end{aligned}
$$

Maximum extend discharge time $\Delta T$ formula:

$$
\frac{\Delta T}{T_{b o}}=\frac{\varepsilon \delta \sqrt{D}}{1-\varepsilon \delta \sqrt{D}}
$$

In the formula:

$R_{b}, R_{c}$ - Internal resistance of battery and internal resistance of ultracapacitor

$I_{0}$ - Amplitude of output current

$D$-Pulse duty cycle of inrush current

$\mathcal{E}$-Energy savings coefficient

$m$-Ratio of total number of serial ultracapacitors and shunt ultracapacitors.

$\delta$-Ratio of amplitude of the load current and short-circuit current of battery branch.

Seen from the above formulae, we know that the superior characteristics of the hybrid energy storage have relation with internal resisance and pulse duty of load current. 


\section{Potential applications}

\subsection{Energy savings}

Frequency transformer has been widely used in the chemical industry, power and other fields. However, most of the frequency control systems brake by energy consumption ${ }^{[8]}$, which result in tremendous waste, because energy come from braking is consumed in the form of heat on resistance, and the utilization ratio of energy is decreased. Hybrid energy storage system based on the ultracapacitor, connecting to the DC bus of the converter can be used to store energy come from braking. Hybrid system releases energy when energy in power system is insufficient to provide power support.

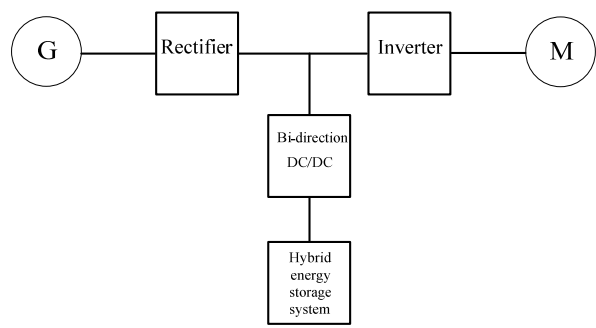

Fig.4 Sketch diagram of hybrid energy storage system for energy savings

\subsection{Enhance performance of DC system}

DC system in substation is an important part of relay protection, control system, communication, and accidental emergency power supply ${ }^{[12,13]}$. For most of substations, lead-acid battery are often used as energy storage unit for DC system, but it is charged and discharged through chemical reaction, the capacity of battery and efficiency of charge and discharge will decrease with increasing times of charging and discharging. In addition, impurities in electrolyte and self-discharge have great impact on conversion efficiency and lifetime of battery. Meanwhile, lead-acid batteries cannot quickly respond to the pulse current, which will result in huge energy loss on internal resistance. Because ultracapacitor has capability of fast reaction and rapid charge and discharge, traditional lead-acid battery and ultracapacitor can be combined together to form a kind of hybrid energy storage system for enhancing power supply reliability of DC system.

\subsection{Start-up of motor}

In some of large chemical plants, frequency converter is often equipped on feed-line with motor load like fans to reduce inrush current when the motor starts (soft start), aiming at relieve impact on stable operation of the system. After motor starts and operates normally, frequency converter will be bypassed. This strategy not only seriously reduces the utilization of the equipment, but also greatly increases the cost of the investment. Hybrid energy storage system based on ultracapacitor can cope with these problems. When motor starts, hybrid system can make a rapid response to inrush start current to provide power support, then motor will quickly and smoothly starts. When motor brakes or energy in power system is surplus, hybrid system will be charged, extra energy has been recovered, and the objective of energy savings and enhancing utilization of energy and equipment is realized. There is no need to equip one frequency converter on each feed-line, all what need are just inverter with bi-direction power function and several ultracapacitors, and investment cost is finally reduced.

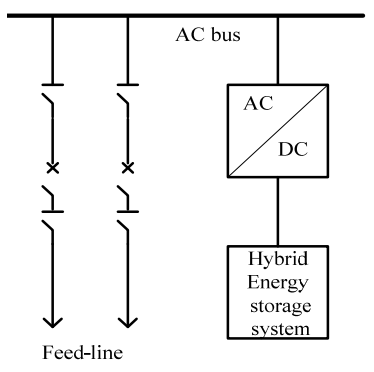

Fig.5 Main connection with hybrid energy storage system based on ultracapacitor

\section{Summary}


Ultracapacitor is a novel storage device with superior performance and broad market prospects. The development of renewable generation, promotion of electric vehicles, and construction of smart grid accelerate research and production of ultracapacitor. With the improvement of manufacturing processes and reduction of production costs, ultracapacitor must be widely used in electric power, industries, and communications filed.

\section{References}

[1] Burke,A.Ultracapacitors:why,how,and where is the technology[J].Journal of power sources.vol.91,pp.37-50.(2000)

[2] Yu Ling-yu,Feng Yu-ping,Supercapacitor Developments in the World,Electronic.(2008)

[3] Wang Zhen-hao,Zhang Yan-qi,Li Guo-qing,Xin Ye-chun,Zhang Shao-jie,Research on Hybrid Energy Storage for DC System of Substations and Power Plants Based on SuperCapacitors,Power System Technology, Vol. 34 No. 4.(2010)

[4] R.A.Dougal,Shengyi Liu, Ralph E.White.Power and Life Extension of Battery-Ultracapacitor Hybrids.IEEE Transaction on Components and Pacjaging Technologies,Vol.25,No.1.(2002)

[5] Conway B E.Transition From Supercapacitor to Battery Behavior in Electrochemical Energy Storage.IEEE,(1990)319-327.

[6] Yuan Guo-hui,Electrochemical Capacitor,Beijing:Chemical Industry Press.(2006)

[7] Zhang Na,Zhang Hong-bao,Research and progress of electrochemical supercapacitor,Applied Science and Technology,30(9):54-30.(2003)

[8] Wang Si-bo,Wei Tong-zhen,Qi Zhi-ping,Energy Saving System Based on Supercapacitor,Proceedings of the CSEE,Vol.30 No.9(2010)

[9] Lijun Gao, Roger A. Dougal, Shengyi Liu. Power Enhancement of an Actively Controlled Battery/Ultracapacitor Hybrid.IEEE Transactions on Power Electronics, Vol.20,No.1(2005)

[10] Ran Niu, Hai Yang.Modeling and Identification of Electric Double-Layer Super-capacitors.(2011)

[11] Li Hai-dong,Qi Xin-chun,Qi Zhiping, The Application Model of the eElectric Double-layer Capacitor,Battery Bimonthly.(2007)

[12] Hou Yun-hong,Guo Ya-chang,Miao Mei,Discussion of Configuration Program of DC System in Substation,Shanxi Electric Power.(2009)

[13] Li Jian,ZHong Hui,Zhong Hai-yun,Application and Design of Supercapacitor,Chinese Journal of Power Source,28(6):388-391.(2004)

[14] Jiri K Nor,Dor,David R Smith.Very Fast Battery Charging and Battery Energy Management.Proc.of the 12th International Electric Vehicle Symposium.(1992) 